\title{
FUNÇÃO DOS INGREDIENTES NA CONSISTÊNCIA DA MASSA E NAS CARACTERÍSTICAS DO PÃO DE GUEIJO'
}

\author{
Joelma PEREIRA2,*, César F. CIACCO ${ }^{3}$, Evódio R. VILELA², Rosemary G. F. A. PEREIRA²
}

\begin{abstract}
RESUMO
O processo de fabricação de pão de queijo envolve basicamente escaldamento do polvilho com leite, água e óleo, amassamento com ovo, adição de queijo e assamento. Este trabalho teve como objetivo estudar a função dos ingredientes na consistência da massa e nas características dos pães de queijo produzidos. As massas foram obtidas de $100 \%$ polvilho azedo (PA), 100\% polvilho doce (PD), $70 \%$ polvilho azedo $+30 \%$ polvilho doce (PS) e $50 \%$ polvilho azedo $+50 \%$ polvilho doce (PC), combinados com formulações: completa, com todos os ingredientes (FC), sem leite, mas com água (SL), sem ovo (SO) e sem queijo. As massas foram desenvolvidas no Farinógrafo Brabender, o qual teve deste modo sua forma de utilização ampliada, e a evolução da consistência destas massas foi acompanhada por meio dos gráficos gerados. As massas foram moldadas e assadas e as características dos pães analisadas. Durante o escaldamento e mistura houve elevação dos valores de consistência, o ovo causou queda drástica desta consistência e o queijo provocou nova elevação, tornando a massa moldável. A consistência das massas foi mais afetada pelas formulações sendo que, as sem leite (SL) apresentaram os maiores registros; as sem queijo (SQ) as menos consistentes. As massas sem ovo (SO) apresentaram-se secas, duras, despedaçandose quando manuseadas. Pães de queijo FC e SQ apresentaram maior volume específico e maior diâmetro. Pães de queijo SO apresentaram menor indice de expansão. O ovo e o queijo desempenharam importante papel na obtenção de massas facilmente moldáveis, originando pães de queijo com boas características estruturais.

Palavras-chave: pão de queijo; função dos ingredientes; consistência da massa; características físicas do pão de queijo.
\end{abstract}

\section{SUMMARY}

FUNCTION OF THE INGREDIENTS IN THE CONSISTENCY OF THE DOUGH AND IN THE CHARACTERISTICS OF THE CHEESE BREADS. The process of production cheese bread involves scalding of the cassava starch with milk, water and oil, kneading with egg, addition of cheese and baking. This work had as objective to study the function of the ingredients in the consistency of the dough and in the characteristics of the produced cheese breads. The doughs were obtained of $100 \%$ sour starch (PA), 100\% sweet starch (PD), $70 \%$ sour $+30 \%$ sweet (PS) and 50\% sour $+50 \%$ sweet (PC), combined with the following formulations: with all the ingredients (FC), without milk, but with water (SL), no egg (SO) and no chesse (SQ). The doughs were developed in Farinograph Brabender and the evolution of their consistency were accompanied by graphs. The doughs were molded and baked and the characteristics of the breads cheese were analyzed. It was observed an increase of the consistency values during the scalding and mixture, the egg caused drastic fall of this consistency while the cheese an elevation, turning the dough moldable. The consistency of the doughs were more affected by the formulation and the without milk formulations (SL) presented the highest values; the without chesse formulations (SQ) presented lowest consistency. The doughs without egg (SO) were dry, hard, being cut into pieces when handled. Cheese breads FC and SQ presented high specific volume and larger diameter. Cheese breads SO presented smaller expandion index. The egg and the cheese played important role in the obtaining of doughs moldable easily, originating cheese breads with good structural characteristics. Keywords: cheese bread; ingredients; consistency of the doughs; physical characteristics.

\section{1 - INTRODUÇÃO}

Os polvilhos doce e azedo destacam-se entre os principais produtos derivados da mandioca e são largamente utilizados como ingredientes básicos na fabricação de biscoitos e pão de queijo, sendo este último considerado originário de Minas Gerais.

Segundo a Resolução 12/78 da Comissão Nacional de Normas e Padrões para Alimentos do Ministério da Saúde - CNNPA/MS [5], polvilho ou fécula de mandioca é o produto extraído da mandioca. Por meio de normas técnicas especiais relativas a alimentos e bebidas, o polvilho é classificado em doce e azedo, tendo por base apenas o teor de acidez. Para o produto fermentado, a

\footnotetext{
Recebido para publicação em 02/05/2001. Aceito para publicação em 20/07/2004 (000635).

2. Departamento de Ciências dos Alimentos - Universidade Federal de Lavras, Caixa Postal 37, CEP: 37200-000, Lavras-MG. E-mail:joper@ufla.br. Parte da tese defendida na UFLA em 08/02/2001.

3. Departamento de Tecnologia de Alimentos - Faculdade de Engenharia de Alimentos - Universidade Estadual de Campinas - Cidade Universitária Zeferino Vaz. Barão Geraldo, CEP: 13085-970, Campinas-SP. * A quem a correspondência deve ser enviada.
}

acidez deve ser, no máximo, de $5 \mathrm{~mL}$ de $\mathrm{NaOH} 1 \mathrm{~N} / 100 \mathrm{~g}$ e para o não-fermentado de $1 \mathrm{~mL}$ de $\mathrm{NaOH} 1 \mathrm{~N} / 100 \mathrm{~g}$. Para outras características, os valores são idênticos: umidade máxima de $14 \% \mathrm{p} / \mathrm{p}$, teor mínimo de amido de $80 \% \mathrm{p} / \mathrm{p}$ e resíduo mineral fixo máximo de $0,5 \% \mathrm{p} / \mathrm{p}$, conforme ABIA [3].

Além de ser uma fonte reconhecida de carboidratos, o pão de queijo também é um produto de panificação isento de glúten, o que o coloca como alimento alternativo para pacientes celíacos, alérgicos às proteínas do trigo.

Sob a denominação de "pão de queijo" podem ser encontrados no mercado diferentes tipos de produtos com características bem distintas. Apesar de não haver uma tecnologia padronizada, o método de fabricação adotado pela grande maioria dos produtores de pão de queijo utiliza como ingredientes básicos polvilho doce e/ou azedo, queijo, óleo e ovos, seguindo um princípio básico de escaldamento do polvilho com água, óleo ou leite, amassamento com ovos, adição de queijo e assamento. O congelamento das massas de pão de queijo propiciou uma ampliação de mercado, interno e externo, que era pouco explorado para este produto. Esta 
evolução evidenciou a necessidade de se padronizar a sua fabricação, a fim de melhorar a sua qualidade.

Em 1997, de acordo com dados da Federação das Indústrias de Minas Gerais (FIEMG), existiam 85 empresas fabricantes de pão de queijo registradas na região metropolitana de Belo Horizonte e cerca de 120 produtores informais em todo o Estado de Minas Gerais. Por outro lado, em 1995, já se estimava a existência de cerca de 500 pontos de venda no país, entre lojas independentes e franqueadas, além de 45 mil padarias e os milhares de produtos informais (Ribas, 1997 e Souza, 1995, citados por JESUS [14]).

Com os avanços na industrialização do pão de queijo empregando-se leite, ovo e queijo em pó, surgiram inúmeras formulações contendo purê de batata, farinha de milho e até mesmo recheios e aromas artificiais. A possibilidade de congelamento da massa de pão de queijo, aumentando a faixa do mercado consumidor, e a grande comercialização das misturas prontas chegando a ocupar o segundo lugar entre os produtos nacionais mais pedidos pelos brasileiros que vivem no exterior [2], mostram que há uma tendência acentuada de crescimento do mercado de pão de queijo. Por outro lado, a ausência de informações sobre o papel dos ingredientes nas características de qualidade do pão de queijo constitui-se em entrave na busca de padrões que permitiriam um melhor controle na qualidade do produto.

A tecnologia de fabricação de pão de queijo com polvilho doce não apresenta diferença quando se utiliza polvilho azedo, mas, ainda assim, observou-se que o pão de queijo produzido com polvilho azedo apresenta maior volume, textura mais porosa com maior número de células de ar, miolo esponjoso, mais leve e elástico, casca lisa e uniforme quando comparado ao pão de queijo produzido com polvilho doce. Entretanto, o pão de queijo feito com polvilho doce tem sua padronização facilitada por apresentar características físicoquímicas mais estáveis [19]. A principal função do amido em produtos de panificação é absorver água e, deste modo, estabelecer a estrutura do produto [12, 13].

O leite tem sido utilizado na fabricação do pão de queijo substituindo parcial ou totalmente a água [20]. Nas receitas tradicionais, o leite é adicionado à mistura de escaldamento do polvilho e a gordura presente no leite confere melhor aparência ao produto final; as proteínas contribuem para a maciez e umidade, enquanto os sais minerais alteram a consistência da massa aumentando o valor nutritivo do pão de queijo [4, 7, 21]. O leite ajuda o queijo na estruturação e texturização da massa [26] apresentando melhor sabor e maior maciez do miolo, possivelmente por permitir maior retenção de umidade, melhor coloração da casca, conforme CANAVESI et al. [6] e PEREIRA [19].

A água é utilizada na fabricação do pão de queijo para dissolver os ingredientes solúveis, influenciando também no escaldamento do polvilho [19]. A quantidade de água é fundamental para o inchamento do grânulo de amido e sua quantidade depende dos ingredientes da fórmula e do processo de panificação utilizados, consti- tuindo o meio dispersante para os outros ingredientes da formulação, além de favorecer o crescimento do pão durante o assamento. A adição de quantidades crescentes de água à massa torna-a mais macia e pegajosa, enquanto que sua escassez torna-a dura e sem aderência (Bloskma, 1964, citado por LOURES, 1989 [16]).

Em produtos de panificação, as gorduras contribuem para as propriedades de mastigação, conferindo-lhes maciez. O aumento dos conteúdos de gordura, além do efeito amaciador, contribui para dar maior brilho e uma melhor aparência [1, 9], como também atua no valor nutricional, sendo a mais concentrada fonte de energia presente nos alimentos [1, 23].

De acordo com CANAVESI et al. [6], no pão de queijo a gordura atua como um lubrificante molecular, ajudando a massa a ter maior extensibilidade, contribuindo para maior elasticidade e melhor textura do miolo. Além disso, melhora o aspecto da crosta, sendo que a adição de gordura vegetal produz massa menos oleosa e o produto obtido apresenta maior elasticidade e melhor aspecto quando comparado à adição de óleo de soja.

$\mathrm{O}$ ovo tem como propriedades funcionais a coagulação, a capacidade espumante, a capacidade emulsificante e a contribuição nutricional, servindo também como agente corante e de sabor e aroma, originando pães de queijo com melhor estrutura, textura mais leve e aerada, maior volume, característica de liga, cor amarela natural, além do fornecimento de proteínas, vitaminas (A, D e E) e minerais [15, 26].

Na fabricação do pão de queijo podem ser utilizados diversos tipos de queijo, sendo mais comumente utilizados os tipos mussarela, parmesão, minas curado e minas padrão [14]. Esta variedade constitui um grande fator de variação nas características do pão de queijo, pois, mesmo utilizando-se de um mesmo tipo de queijo, sabe-se que não existe no país um padrão de identidade característico para este produto [18, 21].

O queijo contribui para o aroma e o sabor típicos dos produtos [20], complementando a estruturação do miolo do pão de queijo e auxilia na obtenção de melhor textura do produto final $[20,26]$, pois contribui para a elasticidade e melhor aspecto da casca, além de conferir uma maior maciez e uniformidade às células do miolo [14].

O sal contribui para o sabor, sendo utilizado o cloreto de sódio comum iodado na fabricação do pão de queijo em proporções de $1 \%$ a $2,5 \%$ em relação ao peso do polvilho [14, 19].

Este trabalho foi desenvolvido com o objetivo de avaliar o papel dos ingredientes na estruturação da massa, principalmente na sua consistência, e nas características dos pães de queijo obtidos.

\section{2 - MATERIAL E MÉTODOS}

O experimento foi conduzido no Laboratório de Grãos e Cereais, do Departamento de Ciência dos Alimentos, da Universidade Federal de Lavras (UFLA), em Lavras, Minas Gerais. 


\section{1 - Material}

Todo o polvilho utilizado no experimento foi cedido pela Indústria de Polvilho TUP-GUAR, de Conceição dos Ouros, Minas Gerais.

Os polvilhos doce e azedo, bem como as misturas de polvilho PS ( $70 \%$ polvilho azedo $+30 \%$ polvilho doce) e PC $(50 \%$ polvilho azedo $+50 \%$ polvilho doce) foram homogeneizados em um misturador tipo cone com capacidade para $50 \mathrm{~kg}$, por um tempo de dez minutos.

Foi utilizado leite do tipo integral em embalagem longa vida, óleo de soja comercial, sal iodado comercial, ovos brancos frescos provenientes sempre de uma mesma granja, queijo tipo parmesão com 60 dias de maturação, fabricados no setor de Laticínios da Universidade Federal de Lavras e água potável.

As massas e os pães de queijo analisados foram obtidos de polvilho azedo (PA), polvilho doce (PD), 70\% azedo $+30 \%$ doce (PS) e 50\% azedo $+50 \%$ doce (PC), sendo cada tipo de massa desenvolvida com um dos tipos de polvilho e uma das formulações, originando as massas PAFC, PDFC, PSFC, PCFC, PASL, PDSL, PSSL, PCSL, PASO, PDSO, PSSO, PCSO, PASQ, PDSQ, PSSQ e PCSQ. A relação dos ingredientes utilizados nas diferentes formulações encontra-se na Tabela 1 e a porcentagem dos ingredientes, quando utilizados, nas formulações de pão de queijo em relação ao polvilho e em relação ao total de ingredientes encontra-se na Tabela 2.

TABELA 1. Composição das formulações utilizadas para produção de pão de queijo.

\begin{tabular}{lccccccc}
\hline Formulações & Polvilho & Leite & Água & Óleo & Sal & Ovo & Queijo \\
\hline FC - Completa & $\mathrm{X}$ & $\mathrm{X}$ & & $\mathrm{X}$ & $\mathrm{X}$ & $\mathrm{X}$ & $\mathrm{X}$ \\
SL - Sem Leite & $\mathrm{X}$ & & $\mathrm{X}$ & $\mathrm{X}$ & $\mathrm{X}$ & $\mathrm{X}$ & $\mathrm{X}$ \\
SO - Sem Ovo & $\mathrm{X}$ & $\mathrm{X}$ & & $\mathrm{X}$ & $\mathrm{X}$ & & $\mathrm{X}$ \\
SQ - Sem queijo & $\mathrm{X}$ & $\mathrm{X}$ & & $\mathrm{X}$ & $\mathrm{X}$ & $\mathrm{X}$ & \\
\hline
\end{tabular}

TABELA 2. Quantidade dos ingredientes utilizados nas formulações de pão de queijo e suas percentagens em relação à quantidade de polvilho e a todos os ingredientes.

\begin{tabular}{lccc}
\hline Ingredientes & Quantidades & $\begin{array}{c}\text { \% em relação ao } \\
\text { polvilho }\end{array}$ & $\begin{array}{c}\text { \% em relação a todos } \\
\text { os ingredientes }\end{array}$ \\
\hline Polvilho & $250,00 \mathrm{~g}$ & 100,00 & 45,23 \\
Leite ou água & $135,62 \mathrm{~g}$ & 54,26 & 24,54 \\
Óleo & $41,10 \mathrm{~g}$ & 16,44 & 7,44 \\
Sal & $5,50 \mathrm{~g}$ & 2,20 & 1,00 \\
Ovo & $58,00 \mathrm{~g}$ & 23,20 & 10,49 \\
Queijo & $62,50 \mathrm{~g}$ & 25,00 & 11,31 \\
\hline
\end{tabular}

\section{2 - Consistência das massas}

A obtenção das massas foi feita no Farinógrafo Brabender, modelo no 810101 , utilizando misturador com capacidade para 300 g e pás misturadoras reguladas para 31,5rpm. A unidade de medida do farinógrafo é Unidade Farinográfica (UF).

O desenvolvimento de cada massa no farinógrafo foi realizado colocando-se uma amostra de $250 \mathrm{~g}$ de pol- vilho no misturador do farinógrafo e depois de iniciada a mistura, foi feito o escaldamento com uma mistura fervente de leite + óleo + sal, no caso das formulações completa (FC), sem ovo (SO) e sem queijo (SQ). Para formulações sem leite (SL) fez-se o escaldamento com água + óleo + sal. Após cinco minutos do escaldamento, foi adicionado o ovo fresco, o qual teve a clara e a gema previamente misturadas, para facilitar a sua adição, para as formulações completa (FC), sem leite (SL) e sem queijo (SQ). A seguir, após três minutos, o aparelho foi desligado e adicionado o queijo às formulações completa (FC), sem leite (SL) e sem ovo (SO) e novamente o aparelho foi ligado até que não variasse a consistência, aproximadamente três minutos, quando foi desligado e a massa foi retirada.

A evolução da consistência da massa foi determinada diretamente, por meio dos gráficos gerados pelo aparelho.

\section{3 - Obtenção dos pães de queijo}

Após a retirada da massa do farinógrafo, esta foi moldada com o auxílio de um tubo de PVC, com três centímetros de diâmetro e três centímetros de altura. $\mathrm{O}$ acabamento da moldagem foi feito manualmente para que os pães adquirissem um formato redondo. As massas foram assadas em forno elétrico a $180^{\circ} \mathrm{C}$. O tempo de assamento foi variável de acordo com a formulação, entre 20 e 25 minutos. Um estudo prévio do tempo e da temperatura de forneamento foi realizado por GASPARI \& PEREIRA [11] tendo por base, principalmente, a coloração externa e a textura do miolo.

\section{4 - Caracterização física dos pães de queijo}

O diâmetro e a altura da massa moldada foram determinados por meio de um paquímetro e seu peso determinado em balança semi-analítica. Essas mesmas medidas também foram feitas nos pães de queijo.

Com esses dados o volume, o volume específico e o indice de expansão foram calculados conforme as equações apresentadas a seguir:

$$
\begin{array}{r}
\text { - volume }=4 / 3 \times \pi \times \mathrm{r}^{3} \text { (onde } \mathrm{r}=\text { raio) } \\
\text { - volume específico }=\text { volume } / \text { peso }(\mathrm{g}) \\
\text { - indice de expansão }=\text { diâmetro do pão de queijo }+ \\
\frac{\text { altura do pão de queijo) } / 2}{(\text { diâmetro da massa moldada }+} \\
\text { altura da massa moldada) } / 2
\end{array}
$$

Neste experimento optou-se por não utilizar o método de deslocamento do painço para determinação do volume dos pães de queijo porque, principalmente, os pães de queijo obtidos de formulações sem queijo apresentaram rachaduras mais profundas, por onde as sementes do painço poderiam penetrar, o que causaria maior alteração do volume do que o método da fórmula matemática utilizado neste trabalho. 


\section{5 - Análise estatística}

Os dados foram analisados utilizando-se o programa SISVAR, desenvolvido na Universidade Federal de Lavras por FERREIRA [10], sendo aplicado o teste de Scott e Knott (1974) para a comparação das médias, quando as diferenças se mostraram significativas pelo teste de $\mathrm{F}$, a $5 \%$ de probabilidade. O teste de Scott e Knott foi escolhido por diferenciar bem os tratamentos, ao apresentando "encavalamento" entre as médias. O delineamento experimental utilizado foi o inteiramente casualizado, sendo os tratamentos dispostos em esquema fatorial com 4 tipos de polvilho $\mathrm{x} 4$ formulações x 3 repetições.

\section{3 - RESULTADOS E DISCUSSÃO}

Apesar de o farinógrafo não ser um equipamento desenvolvido para análise de consistência de massas de pão de queijo, este aparelho foi utilizado para a fabricação das massas e para o registro da resistência delas aos movimentos das pás do aparelho. Dessa forma, foi possivel realizar um acompanhamento da evolução da consistência, registrada no aparelho e expressa em unidades farinográficas (UF).

Houve diferenças entre massas contendo polvilho doce ou azedo, sendo a consistência dessa última no escaldamento menor do que a obtida pelo polvilho doce (Figura 1). Tal fato pode ser atribuído à fermentação sofrida pelo PA que ocasiona uma absorção de água mais rápida do que os outros polvilhos, atingindo, portanto, o "máximo" de sua consistência antes dos outros polvilhos, comportamento este já observado por NAKAMURA, MORAIS \& MARTUCCI [17] que afirmaram que a fermentação confere ao polvilho azedo maior solubilidade e maior poder de inchamento em relação ao polvilho não-fermentado.

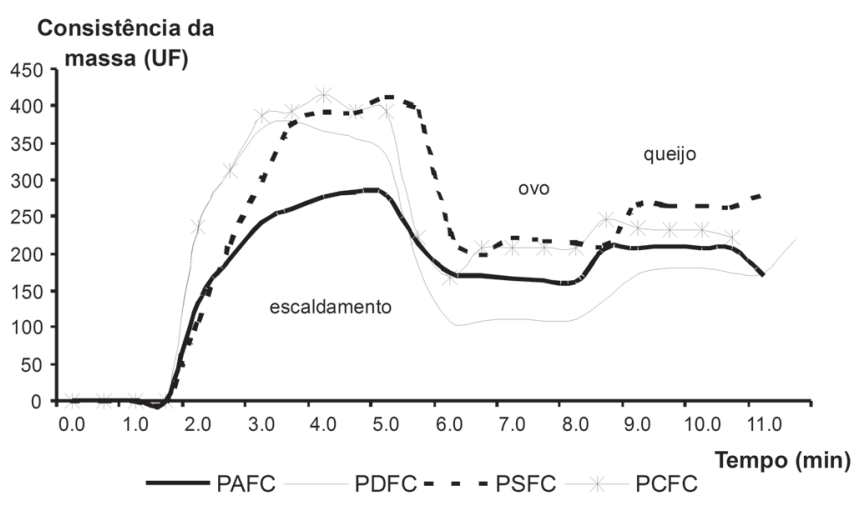

FIGURA 1. Curvas de consistência de massas de pão de queijo para os diferentes tipos de polvilho nas formulações completas (PAFC, PDFC, PSFC e PCFC), em função do tempo.

Durante o escaldamento ocorre uma gelatinização parcial do polvilho e quando este gelatiniza compete com outros componentes da mistura pela água do sistema, além de formar pastas muito viscosas e instáveis [25].
De maneira geral, o escaldamento provocou um aumento nos valores da consistência enquanto a adição de ovo provocou um decréscimo nesse parâmetro e o queijo um ligeiro aumento.

Todas estas massas, produzidas com todos os ingredientes da formulação, tendo como variável apenas o tipo de polvilho, foram retiradas do farinógrafo com certa facilidade, pois não estavam aderidas excessivamente ao aparelho e apresentaram também uma ótima plasticidade ao serem moldadas.

Quando o escaldamento se procedeu com o emprego de água, óleo e sal, os gráficos de consistência de massas da formulação SL (Figura 2) apresentaram valores em UF bem maiores do que nas formulações FC. Esse resultado indica que houve uma maior "resistência" das massas em serem misturadas, tendo os maiores valores sido registrados com as massas PDSL e PCSL. Com a adição do ovo, as massas registraram uma queda bastante acentuada na consistência, voltando a se elevar um pouco com a adição do queijo. Também neste experimento foi observado que a adição de ovo e queijo levou as massas a valores de consistência em torno de 300 a 400UF, relativamente próximos aos obtidos anteriormente com as formulações completas (200 a 300UF).

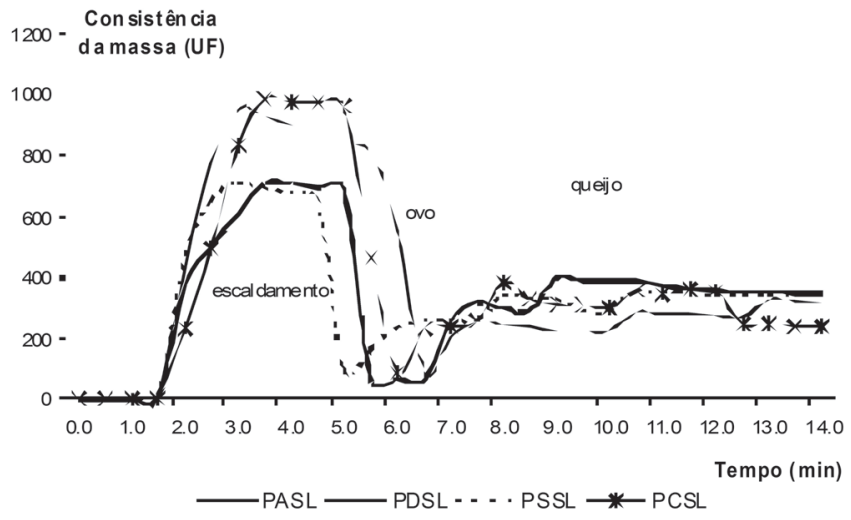

FIGURA 2. Curvas de consistência de massas de pão para os diferentes tipos de polvilho nas formulações sem leite (PASL, PDSL, PSSL e PCSL), em função do tempo.

As massas sem leite apresentaram uma textura um pouco mais pegajosa do que as massas com formulação completa, não saindo do aparelho com tanta facilidade quanto as anteriores, confirmando o comentário de ZELAYA [26] de que o leite ajuda na estruturação e texturização da massa.

Mas apesar disto, as massas sem leite eram fáceis de serem modeladas e também conservaram seu formato até o assamento, comprovando que a água utilizada neste tipo de formulação exerceu satisfatoriamente as funções mencionadas por PEREIRA [19]: alterar a consistência e a elasticidade da massa de pão de queijo, que deve ser suficientemente macia para ser moldada, suficientemente rígida para manutenção da forma até que esteja congelada, e apresentar um certo grau de elasticidade para se expandir sem romper durante o assamento. 
Em formulações sem ovo (Figura 3), as massas apresentaram uma queda de consistência menos acentuada com adição do queijo após o escaldamento com leite, óleo e sal, ou seja, entre 5 e 6 minutos de mistura, aproximadamente. Esta queda mais suave resultou numa massa mais dura, esfarelenta, sem aderência no aparelho e nos moldes, porém difícil de ser moldada exatamente por não apresentar uma "liga", ressaltando a importância do ovo sobre esta propriedade.

Nos minutos finais da mistura, a formulação PCSO foi apresentando uma queda constante na consistência. No caso destas formulações, consistências menores, não indicaram de forma alguma, massas mais macias e sim massas mais esfarelentas. O formato das massas moldadas não sofreu modificações até o assamento.

Essas características podem ser decorrentes da ausência dos lipídios presentes na gema do ovo, pois massas de pão de queijo com quantidade insuficiente de óleos e gorduras requerem uma maior quantidade de água para produzir uma massa de boa consistência e proporcionar produtos mais macios.

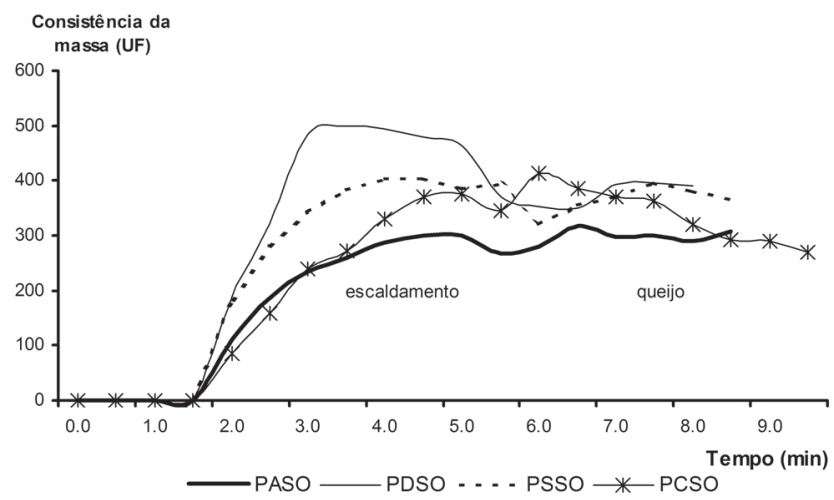

FIGURA 3. Curvas de consistência de massas de pão de queijo para os diferentes tipos de polvilho nas formulações sem ovo (PASO, PDSO, PSSO e PCSO), em função do tempo.

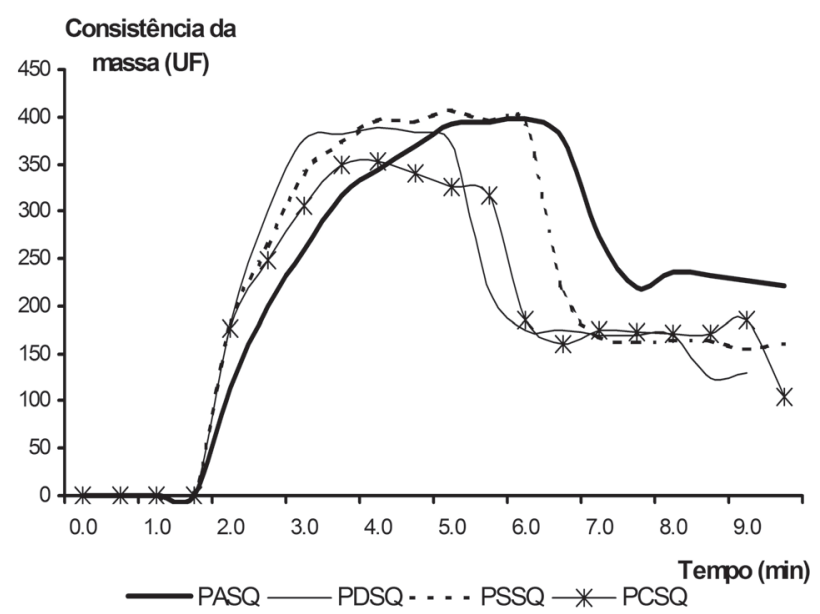

FIGURA 4. Curvas de consistência de massas de pão de queijo para diferentes tipos de polvilho nas formulações sem queijo (PASQ, PDSQ, PSSQ e PCSQ), em função do tempo.
As curvas de consistência de massas das formulações SQ são mostradas na Figura 4. Até o momento da adição do ovo, o comportamento foi o mesmo desenvolvido pela formulação $\mathrm{FC}$, tendo um aumento em UF no escaldamento (leite, óleo e sal) sofrendo uma queda com a adição do ovo. As massas eram muito moles, com grande aderência, difíceis de serem retiradas do farinógrafo e moldadas com maior dificuldade. Houve, inclusive, dificuldade de retirá-las dos moldes e não mantiveram o formato redondo inicial por muito tempo, pois a massa era excessivamente mole, o que confirmou o papel do queijo na estruturação da massa.

Quanto à consistência final das massas de pão de queijo, ou seja, a consistência da massa após a colocação de todos os ingredientes e após o tempo de mistura, não houve influência significativa dos tipos de polvilho, mas sim do tipo de formulação utilizada. Isto indica que a consistência final das massas de pão de queijo, apesar das variações sofridas durante sua evolução, é independente do tipo de polvilho e dependente apenas da formulação, conforme observado na Tabela 3.

TABELA 3. Quadrados médios da análise de variância e respectivos niveis de significância para consistência final das massas em função dos tipos de polvilho e das formulações.

\begin{tabular}{lcc}
\hline \multirow{2}{*}{ Fontes de variação } & \multirow{2}{*}{ GL } & Quadrados médios \\
\cline { 3 - 3 } & & Consistência final das massas \\
\hline Polvilho (A) & 3 & $2320,8334^{\text {ns }}$ \\
Formulação (B) & 3 & $54636,1112^{*}$ \\
A x B & 9 & $5344,90^{\text {ns }}$ \\
Erro & 32 & 7156,7708 \\
\hline CV & & 31,8735 \\
\hline significativo a 5\%, pelo Teste de F. & \\
ns não-significativo a 5\%, pelo Teste de F.
\end{tabular}

Observou-se que mesmo apresentando os mesmos valores em UF, as massas possuiam diferentes características durante o manuseio. As massas de formulação completa (FC) e as massas sem queijo (SQ) eram muito macias, plásticas e moles, sendo que as massas SQ eram bem mais moles e pegajosas do que as FC. As massas de formulações sem leite (SL) e sem ovo (SO), também apresentaram diferença quanto ao aspecto geral, pois as massas SL eram facilmente moldadas, com boa plasticidade enquanto as SO eram duras e esfarelentas.

TABELA 4. Guadrados médios da análise de variância e respectivos níveis de significância para volume específico, índice de expansão, diâmetro dos pães de queijo, em função dos tipos de polvilho e das formulações.

\begin{tabular}{lcccc}
\hline \multirow{2}{*}{ Fontes de variação } & \multirow{2}{*}{ GL } & \multicolumn{3}{c}{ Quadrados médios } \\
\cline { 3 - 5 } & & Volume específico & Índice de expansão & Diâmetro \\
\hline Polvilho (A) & 3 & $0,7770^{\text {ns }}$ & $0,3313^{\text {ns }}$ & $0,0938^{\text {ns }}$ \\
Formulação (B) & 3 & $10,0704^{*}$ & $7,4942^{*}$ & $2,6377^{*}$ \\
A x B & 9 & $0,5715^{\text {ns }}$ & $0,3798^{\text {ns }}$ & $0,3283^{*}$ \\
Erro & 32 & 0,3073 & 0,3002 & 0,0614 \\
\hline CV & 19,84 & 20,29 & 5,50 \\
\hline \multicolumn{5}{c}{ significativo a 5\% }
\end{tabular}

significativo a $5 \%$, pelo Teste de $\mathrm{F}$.
ns não-significativo a $5 \%$, pelo Teste de $\mathrm{F}$. 
O volume específico e o índice de expansão dos pães de queijo não foram influenciados pelo tipo de polvilho e, nem pela interação tipo de polvilho versus formulação, mas foram influenciados pela formulação isoladamente. O diâmetro dos pães de queijo foram influenciados pela formulação utilizada e pela interação tipo de polvilho versus formulação, conforme pode ser comprovado pelos dados estatísticos apresentados na Tabela 4.

Os valores médios de volume específico, índice de expansão e diâmetro dos pães de queijo os quais foram influenciados pelas formulações utilizadas são mostrados na Tabela 5.

TABELA 5. Valores médios ${ }^{1}$ de volume específico $\left(\mathrm{cm}^{3} / \mathrm{g}\right)$, indice de expansão e diâmetro $(\mathrm{cm})$ de pães de queijo em função das formulações.

\begin{tabular}{cccc}
\hline Formulações & Volume específico $\left(\mathrm{cm}^{3} / \mathrm{g}\right)$ & Indice de expansão & Diâmetro (cm) \\
\hline FC & $3,30+0,30^{\mathrm{a}}$ & $3,27+0,08^{\mathrm{a}}$ & $4,78+0,15^{\mathrm{a}}$ \\
SL & $2,92+0,15^{\mathrm{a}}$ & $2,77+0,05^{\mathrm{a}}$ & $4,66+0,10^{\mathrm{a}}$ \\
SO & $1,46+0,06^{\mathrm{b}}$ & $1,56+0,04^{\mathrm{b}}$ & $3,80+0,05^{\mathrm{b}}$ \\
SQ & $3,46+0,68^{\mathrm{a}}$ & $3,16+0,04^{\mathrm{a}}$ & $4,77+0,39^{\mathrm{a}}$ \\
\hline
\end{tabular}
Médias seguidas de letras distintas na mesma coluna diferem entre si pelo Teste de
Scott e Knott, (5\%).

Pães de queijo produzidos com as formulações FC e SQ se apresentaram mais leves. A formulação SO produziu pães de queijo mais pesados e também mais duros, típico de produtos amiláceos sem adição de emulsificantes, representados na gema do ovo pelos fosfolipídios, lipoproteínas e proteínas. A ausência dos lipídios do ovo $(10,02 \%$ a $11,80 \%$, em média, de acordo com POWRIE \& NAKAI, [22] pode ter comprometido bastante os pães de queijo, não possibilitando a obtenção de um produto com densidade apropriada, mais leve, como é desejável em pães de queijo. Pães com volume pequeno, crosta escura e miolo denso e acinzentado foram observados por D'APPOLONIA \& MACARTHUR [8] em pães com reduzida quantidade de gordura.

A ausência de ovo nos pães de queijo produzidos com os tipos de polvilho em estudo resultou num produto de menor peso específico, menor índice de expansão e menor diâmetro, conforme visto na Tabela 5, ressaltando mais uma vez a importância do ovo, não só na plasticidade da massa, mas também na capacidade da massa em reter os gases evaporados no forneamento. Pães de queijo com formulações FC e SQ apresentaram os maiores diâmetros enquanto que a estrutura dos pães produzidos sem queijo (SQ), originados de uma massa bastante mole, não foi mantida, entrando em colapso mesmo antes do assamento. Esse achatamento levou a um aumento no diâmetro desses pães. Também foi observado que esses pães apresentaram rachaduras, sugerindo que a ausência do queijo deixou as paredes formadas pelas células do miolo muito frágeis, que se rompem e não conseguem reter os vapores formados.

A Figura 5 mostra os pães de queijo obtidos das formulações estudadas, ilustrando as diferenças entre eles.

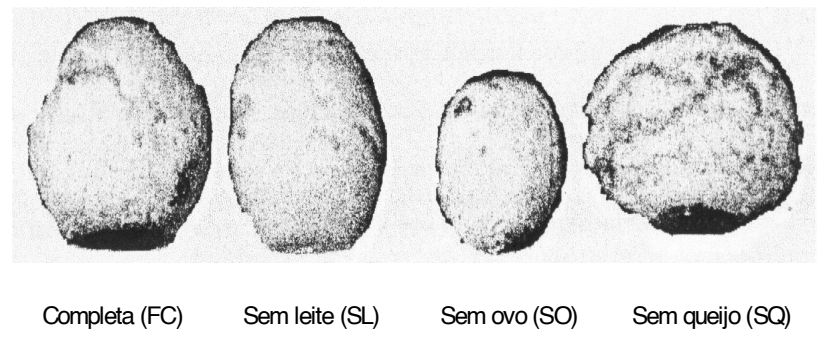

FIGURA 5. Pães de queijo obtidos de formulações completa (FC), sem leite (SL), sem ovo (SO) e sem queijo (SQ).

\section{4 - CONCLUSÕES}

As curvas obtidas no Farinógrafo Brabender, as quais representaram a consistência das massas, mostraram aparências semelhantes: durante o escaldamento houve uma grande aumento da consistência das massas em relação ao início do processo da mistura; a adição do ovo, realizada após o escaldamento provocou uma queda drástica desta consistência; e a adição do queijo realizada como última etapa do processo de obtenção das massas causou um novo aumento da consistência da mistura. A consistência das massas foi mais influenciada pelas formulações, pois somente durante o escaldamento as misturas com polvilho azedo, exceto nas formulações sem queijo, apresentaram menores consistência do que as misturas com polvilho doce devido, eventualmente pela menor solubilidade e menor poder de inchamento deste último.

As massas sem leite apresentaram os maiores valores de consistência e também as maiores alterações a cada ingrediente adicionado. As propriedades das proteínas do leite, principalmente as relacionadas com hidratação e emulsificação podem ter sido determinantes na obtenção de massas que absorvessem água mais rapidamente e ainda que apresentasse menor consistência. A gordura do leite também pode ter contribuído para seu poder emulsificante. As formulações sem ovo foram as mais consistentes e as sem queijo as menos consistentes.

Das características estudadas neste trabalho verificou-se que o tipo de polvilho não exerceu grandes influencias sobre as características reológicas da massa obtidas pelo farinógrafo e sobre as características físicas do pão de queijo, mas estas características foram influenciadas, principalmente, pelo ovo e pelo queijo, cujas presenças nas formulações propiciaram a produção de massas facilmente moldáveis e pães de queijo com melhor aparência.

Apesar de não ser objetivo principal deste trabalho, concluiu-se também que o Farinógrafo Brabender pode ser utilizado no estudo da consistência das massas de pão de queijo.

\section{5 - REFERÊNCIAS BIBLIOGRÁFICAS}

[1] AGUIAR, R.L. Produção e caracterização de massa de pizza pré-assada e congelada. Viçosa, 1995. 88p. (Dis- 
sertação - Mestrado em Ciência e Tecnologia de Alimentos), Universidade Federal de Viçosa (UFV).

[2] AI, que saudades do Brasil. Veja, São Paulo, v. 1671, n. 42 , p. 38 , out. 2000. Seção Holofote.

[3] ASSOCIAÇÃO BRASILEIRA DAS INDÚSTRIAS DE ALIMENTOS (ABIA). Compêndio da legislação de alimentos: atos do Ministério da Saúde. São Paulo, 2000. não paginado.

[4] BENNION, E.B.; BAMFORD, G.S.T. The technology of cake making. Warcester: Billing, 1973. 389p.

[5] BRASIL. Ministério da Saúde. Resolução n. 12/78 da Comissão Nacional de Normas e Padrões para Alimentos. Aprova as normas técnicas especiais do Estado de São Paulo, revistas pelo CNNPA, relativas a alimentos e bebidas. Diário Oficial [da República Federativa do Brasill, Brasília, p. 1, 24 jul. 1978. Seção 1.

[6] CANAVESI, E.; PIROZI, M.R.; MACHADO, P.T.; MINIM, V.P.R. Efeito da concentração dos ingredientes nas características físico-químicas do pão de queijo. In: SIMPÓSIO LATINO AMERICANO DE CIÊNCIA DE ALIMENTOS, 2., 1997, Campinas. Resumos... Campinas: Universidade Estadual de Campinas, 1997. p. 39.

[7] COCUP, R.O.; SANDERSON, W.B. Functionality of dairy ingredients in bakery products. Food Technology, Chicago, v. 41, n. 9, p. 86-90, 1987.

[8] D'APPOLONIA, B.L.; MacARTHUR, L.A. Effect of ingredients on continuos bread-crumb pasting characteristics. Cereal Chemistry, St. Paul, v. 51, p. 195-203, 1974.

[9] EL-DASH, A.A.; CAMARGO, C. de O.; DIAZ, N.M. Fundamentos da tecnologia de panificação. São Paulo: Secretaria da Indústria, Comércio, Ciência e Tecnologia, 1982. 349p. (Série Tecnologia Agroindustrial, 6).

[10] FERREIRA, D.F. Programa Sisvar.exe: sistema de análise de variância. Versão 3.04. [S.1.: s.n], [19—?]. não paginado.

[11] GASPARI, C.; PEREIRA, J. Avaliação tecnológica de misturas de polvilho azedo e doce na formulação de pão de queijo. XII Congresso de Iniciação Científica da UFLA - CICESAL / VII Seminário de Avaliação do PIBIC/CNPq / II Seminário de Avaliação do PBIICTC/ FAPEMIG. Lavras, MG, 15-16 de junho de 1999.

[12] GHIASI K.; HOSENEY, R.C.; VARRIANO-MARSTON, E. Gelatinization of wheat starch. I. Excess-water systems. Cereal Chemistry, St. Paul, v. 59, n. 2, p. 81-85, 1982.

[13] HOSENEY, R.C.; LINEBACK, R.R.; SEIB, P.A. Role of starch in baked foods. The Bakers Digest, Chicago, v. 57, p. 65-70, 1983.

[14] JESUS, C.C. de. Contribuição para a caracterização físico-química e sensorial do pão de queijo. Belo Horizonte: UFMG/Faculdade de Farmácia, 1997. (Dissertação - Mestrado em Ciência de Alimentos).

[15] LEME, L.L. Ovos pasteurizados resfriados e desidratados e sua importância. In: PIZZINATTO, A; ORMENESE, R. de C.S.C. Seminário pão de queijo: ingredientes, formulação e processo. Campinas: Governo do Estado de São Paulo/Secretaria de Agricultura e Abastecimento/
Agência Paulista de Tecnologia dos Agronegócios/Instituto de Tecnologia de Alimentos/Centro de Tecnologia de Cereais e Chocolate, 2000. p. 29-41.

[16] LOURES, A. Obtenção, caracterização e utilização de farinha de banana (Musa sp) em panificação. Belo Horizonte, 1989. 132p. (Dissertação - Mestrado em Ciência de Alimentos). UFMG.

[17] NAKAMURA, I.N.; MORAIS, I.O.; MARTUCCI, E.T. Considerações sobre a tecnologia da fécula de mandioca fermentada: produção, propriedades físico-químicas e aplicação. Científica, Jaboticabal, v. 4, n. 2, p. 196-202, 1976.

[18] OLIVEIRA, J.S.de. Queijo: fundamentos tecnológicos. Campinas: Ícone, 1986. 146p.

[19] PEREIRA, A.J.G. Fatores que afetam a qualidade do pão de queijo. Belo Horizonte: CETEC, 1998. 52p.

[20] PEREIRA, A.J.G.; JESUS, C.C.; LABODSIÈRE, L.H.E.S. Caracterização físico-química, microbiológica e sensorial do pão de queijo. In: SIMPÓSIO LATINO AMERICANO DE CIÊNCIA DE ALIMENTOS, 1997, Campinas. Resumos... Campinas: Universidade Estadual de Campinas, 1995. p. 63.

[21] PEREIRA, A.J.G.; JESUS, C.C.; LABODSIÈRE, L.H.E.S. Influência do tipo de polvilho e das condições de gelatinização sobre a qualidade do pão de queijo. In: CONGRESSO BRASILEIRO DE CIÊNCIA E TECNOLOGIA DE ALIMENTOS, 15., 1996, Poços de Caldas. Resumos... Campinas: Sociedade Brasileira de Ciência e Tecnologia de Alimentos, 1996. p. 3.

[22] POWRIE, W.D.; NAKAI, S. Characteristics of edible fluids of animal origin: eggs. In: FENNEMA, O.R. (ed.). Food chemistry. 2.ed. New York: Marcel Dekker, 1985. p. 829-855.

[23] SEGALL, S.D. Utilização de farinhas mistas na formulação de bolos. Viçosa: UFV, 1994. 104p. (Dissertação - Mestrado em Ciência e Tecnologia de Alimentos).

[24] SWAISGOOD, H.E. Characteristics of edible of animal origin: milk. In: FENNEMA, O.R. (ed.). Food chemistry. 2.ed. New York: Marcel Dekker, 1985. p. 791-827.

[25] VILELA, E.R.; FERREIRA, M.E. Tecnologia de produção e utilização de amido de mandioca. Informe Agropecuário, Belo Horizonte, v. 13, n. 145, p. 69-74, 1987.

[26] ZELAYA, M.P. Tecnología y química de almidones nativos y modificados. In: PIZZINATTO, A; ORMENESE, R. de C.S.C. Seminário pão de queijo: ingredientes, formulação e processo. Campinas: Governo do Estado de São Paulo/Secretaria de Agricultura e Abastecimento/ Agência Paulista de Tecnologia dos Agronegócios/Instituto de Tecnologia de Alimentos/Centro de Tecnologia de Cereais e Chocolate, 2000. p. 15-28.

\section{6 - AGRADECIMENTOS}

À TUP-GUAR Indústria e Comércio Limitada, pela doação dos polvilhos. 